\title{
3D SHAPE OPTIMISATION OF A LOW-PRESSURE TURBINE STAGE
}

\author{
L. WITANOWSKI, P. KLONOWICZ \& P. LAMPART \\ The Szewalski Institute of Fluid-Flow Machinery, Polish Academy of Sciences, Poland.
}

\begin{abstract}
The possibility of reducing the flow losses in low-pressure turbine stage has been investigated in an iterative process using a novel hybrid optimisation algorithm. Values of the maximised objective function that is isentropic efficiency are found from 3D RANS computation of the flowpath geometry, which was being changed during the optimisation process. To secure the global flow conditions, the constraints have been imposed on the mass flow rate and reaction. Among the optimised parameters are stator and rotor twist angles, stator sweep and lean, both straight and compound. Blade profiles remained unchanged during the optimisation. A new hybrid stochastic-deterministic algorithm was used for the optimisation of the flowpath. In the proposed algorithm, the bat algorithm was combined with the direct search method of Nelder-Mead in order to refine the best obtained solution from the standard bat algorithm. The method was tested on a wide variety of well-known test functions. Also, the results of the optimisation of the other stochastic and deterministic methods were compared and discussed. The optimisation gives new 3D-stage designs with increased efficiency comparing to the original design.

Keywords: CFD, efficiency, hybrid method, low pressure steam turbine, optimisation, swarm intelligence.
\end{abstract}

\section{INTRODUCTION}

The performance and profitability of energetic systems depend fundamentally on turbine characteristics - the lower the turbine efficiency, the lower the system efficiency e.g. steam power plant efficiency [1, 2], ORC efficiency [3], energy storage efficiency [4]. Consequently, system efficiency basically depends on the expander design. The computational fluid dynamics (CFD) tools are extremely useful in the design of high-efficiency turbines because of inaccuracy of empirical loss correlation models [5]. The most important component of the total loss is usually connected with the losses within the blade passages - mainly profile loss and secondary (endwall) loss. Despite the significant amount of models, none of them by far has proven to be really general [6]. This leads to the use of computational fluid dynamics in an intensive way for turbomachinery blade design, but this higher performance must be achieved with fast prototyping and lower cost. The largest computational power cost during efficiency optimisation of turbine is connected with the calculation of values of the objective function, which is obtained from a RANS solver.

Novel methods must be used in order to obtain the global minimum with lower number of calls of the objective function. Among these methods are neural network metamodels [7, 8], Kriging and co-Kriging methods [9] and hybrid stochastic-deterministic algorithms $[2,10-14]$.

In this work, the new hybrid stochastic-deterministic optimisation method was used. The method is a combination of Bat algorithm [15] and Nelder-Mead method [16]. Also, a parametric stator and rotor geometry model has been developed. As shown in this paper, these methods allow one for efficient optimisation of turbine blading system. 


\section{TURBINE MODEL}

The five-stage LP part of a 360 MW steam turbine was presented in Fig. 1. The LP part processes pressure drop from $514.76 \mathrm{kPa}$ to $8.855 \mathrm{kPa}$, inlet temperature is equal to $537.72 \mathrm{~K}$, rotational speed is $3000 \mathrm{rpm}$, steam mass flow rate is $103 \mathrm{~kg} / \mathrm{s}$. The optimisation process was focused on the first stage of the turbine (Fig. 2). The first stage consists of 202 stator and 227 rotor blades. Both have cylindrical geometry.

\section{OPTIMISATION ALGORITHM}

\subsection{Bat algorithm}

Bat algorithm is an optimisation algorithm inspired by echolocation phenomenon of bats and was proposed by Yang in 2010 [15]. Bats use a type of sonar, the echolocation tool, to recognize the prey, avoid obstacles and locate their roosting cervices in the dark $[15,17,18]$. They

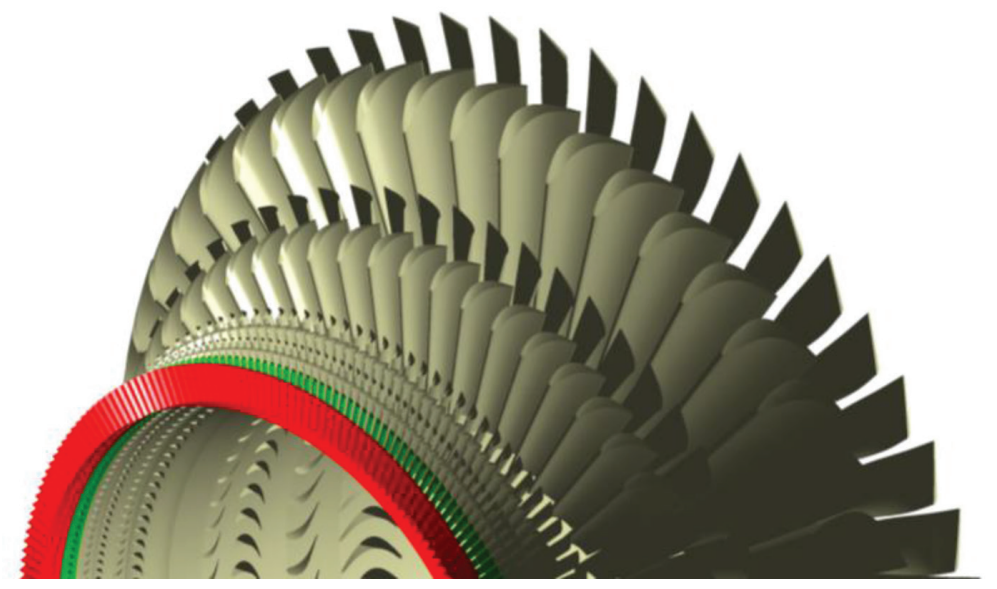

Figure 1: LP part of the steam turbine.

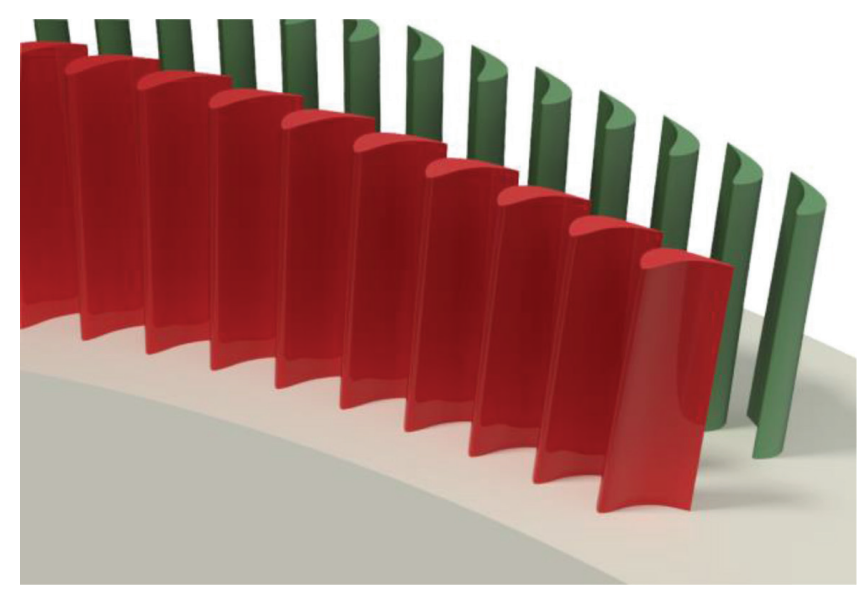

Figure 2: First stage of the turbine LP part. 
emit a very loud sound pulse and listen for the echo that bounces back from the surrounding objects. Their pulse varies in properties and can be correlated with their hunting strategies, depending on the species. Their signal bandwidth varies depending on the species and often increases by using more harmonics [19].

The echolocation characteristics are idealized within the framework of the following rules by benefiting such features of bats [17]:

- All bats use echolocation to sense distance, and they also know the difference between food/prey and background barriers in a seemingly 'magical' way.

- Bats fly randomly with velocity $\mathrm{v}_{\mathrm{i}}$ at position $\mathrm{x}_{\mathrm{i}}$ with a fixed frequency $\mathrm{f}_{\text {min }}$, varying wavelength $\lambda$ and loudness $\mathrm{A}_{0}$ to search for a prey. They can automatically adjust the wavelength (or frequency) of their emitted pulses and adjust the rate of pulse emission $r$ in the range of $[0,1]$, depending on the proximity of their target.

- Although the loudness can vary in many ways, we assume that the loudness varies from a large (positive) $\mathrm{A}_{0}$ to a minimum constant value $\mathrm{A}_{\text {min }}$.

The original bat algorithm is illustrated in Fig. 3 .

\subsection{Nelder-Mead method}

The local direct search method called the Nelder-Mead method [16] is one of the most popular nonlinear optimisation methods. This method was based on the earlier work of Spendley, Hext, and Himsworth [20]. In Nelder-Mead method for a function of $n$ parameters, the algorithm maintains a set of $n+1$ function values and was evaluated at $n+1$ points in parameter space. This set of points defines a simplex in $\mathrm{n}$ dimensions. In two dimensions, the simplex would be a triangle. The worst vertex, where $f(x, y)$ is the largest, is rejected and replaced with a new vertex. A new triangle is formed and the search is continued. The process generates a sequence of triangles (which might have different shapes), for which the function values at the vertices get smaller and smaller. The size of the triangles is reduced and the coordinates of the minimum point are found. To define a complete Nelder-Mead method, four parameters must be specified: reflection, expansion, contraction and shrinkage.

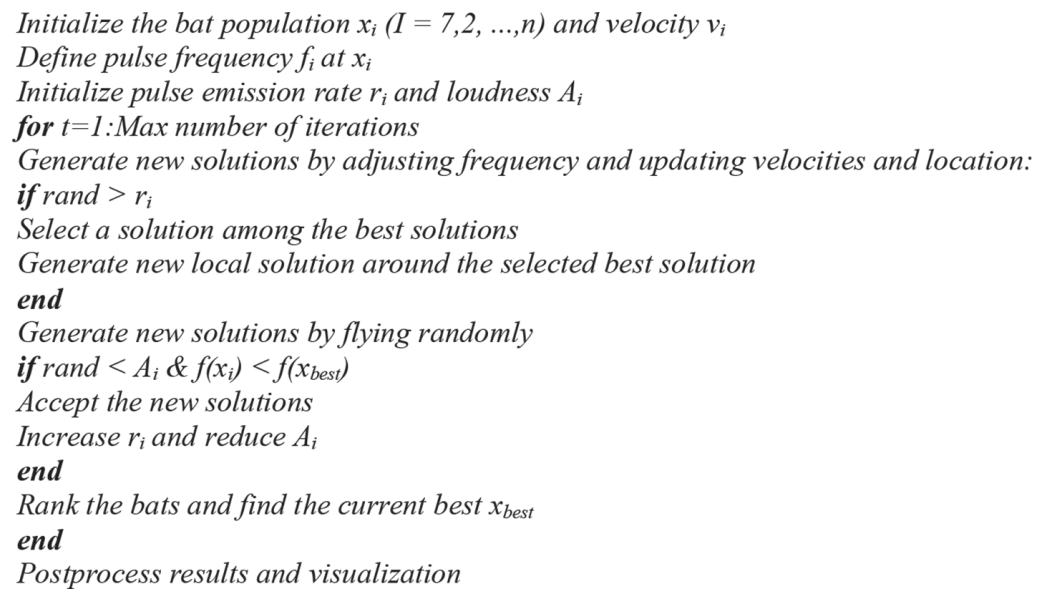

Figure 3: Pseudo-code of bat algorithm. 


\subsection{A novel hybrid algorithm}

The hybridization is a connection of two or more algorithms that run together and complement each other to produce a profitable synergy from their integration [11, 21]. Hybridization aims to combine the advantages of each algorithm, whilst reducing the disadvantages. In hybrids, one algorithm may be incorporated as a sub-algorithm to locate the optimal parameters for another program or different components of algorithm such as mutation crossover that are used to improve another algorithm in the hybrid structure. The hybrid algorithms can be divided into two groups - collaborative hybrids and integrative hybrids. Depending on the combination of the running algorithm, weight of participating of the collaborative hybrids can be grouped as follows: multi-stage, sequential, and parallel.

The proposed Multi-stage Hybrid Bat Algorithm consists of Bat Algorithm and simplex Nelder-Mead method. In standard version of the bat algorithm, the local search of the algorithm is performed only by the solution to satisfy the condition written in Fig. 3 in line 6. Thus, the local search ability of the algorithm depends on a random number compared with the emission rate. The value of the pulse emission rate increases as an iteration proceeds. In order to improve local search, the Nelder-Mead method was used. The steps of new algorithm are started after line 15 . Then the simplex method is run if standard bat algorithm did not improve the best solution. In this modification, all solutions are collected and are ranked before the start of the Nelder-Mead algorithm.

\section{METHODOLOGY}

\subsection{Parametrization}

The parametrization of 3D axial turbine stage was based on several changing parameters: stator twist angle, rotor twist angle, stator simple circumferential lean, rotor simple circumferential lean, stator compound circumferential lean, rotor compound circumferential lean, stator simple axial lean, rotor simple axial lean, stator compound axial lean, rotor compound axial lean. The total number of optimisation parameters was 12: 6 for stator and 6 for rotor. Each parameter was allowed to vary in a prescribed range (bounded optimisation).

\subsubsection{Blade twist angle}

One of the basic method of changing 3D geometry of the blade is twisting of the stator/rotor profiles. An example of this kind of optimisation can be found in literature [22]. This type of solution is often applied for the rotor blades of the MP and LP turbine parts as the flow parameters vary significantly across the blade height. With this approach, the channel throats can be decreased near the endwalls, while they can be increased in the middle section of the blade. The rotor profiles are being rotated with respect to their mass center. In case of the stator profiles, the rotation is performed about the trailing edges. Figure 4 presents the optimized rotor blade along with its initial twisting.

\subsubsection{Simple and compound circumferential lean}

The circumferential lean is one of the solutions reducing the variation of the flow parameters and reaction along the channel height of the LP part. The reduction of the reaction variation, increasing it near the hub and decreasing it near the shroud, leads to reduction of the supersonic flow loss in the boundary layer near the trailing edges. As a consequence, the blade loading near the hub is increased and the separation is reduced. Additionally, the blade tip 

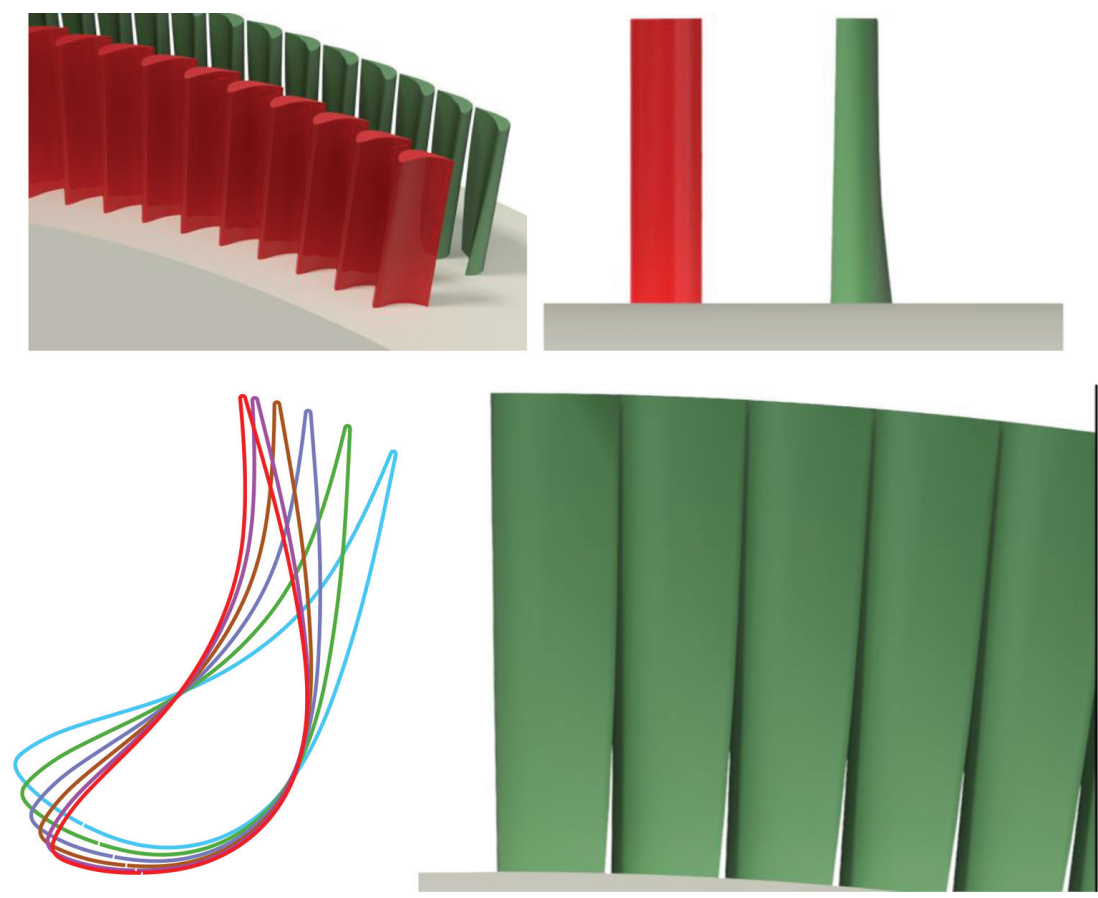

Figure 4: Rotor blade and its twisting.

leakage is reduced. The possibilities of increasing the efficiency depend on the actual loading which in case of the last stages can change in relatively wide range. The best results are obtained in the range of low loadings. Also, the variation of the stator outflow angle is reduced along the blade height which is beneficial from the point of view of the rotor blade for which the twisting level can be decreased [23].

The comparison of the original stage geometry, stage with rotor simple lean and rotor compound lean has been presented in Figs. 5-7.

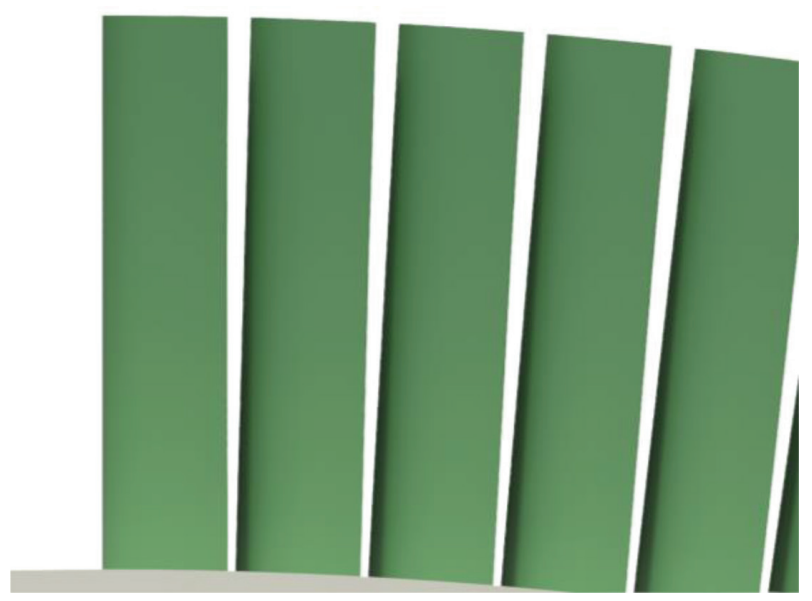

Figure 5: The front view of the original rotor. 


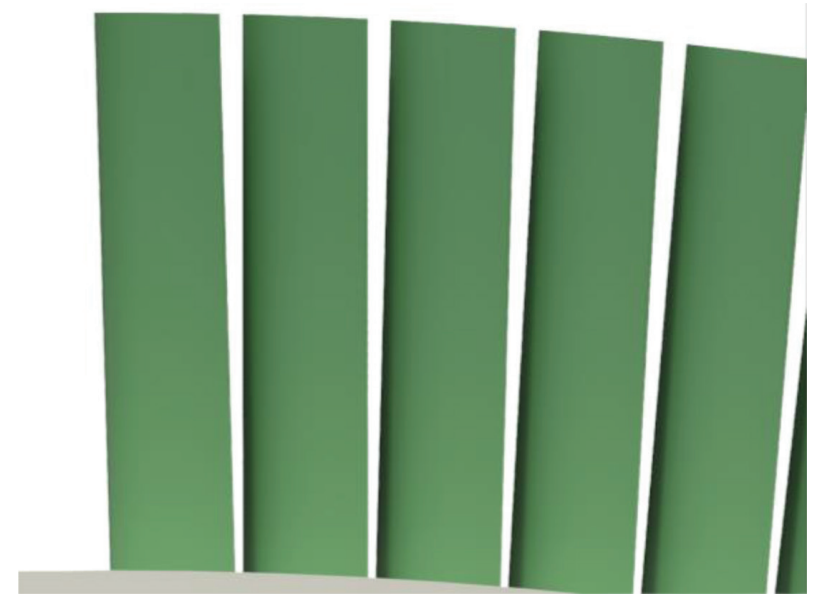

Figure 6: The front view of the rotor with simple circumferential lean.

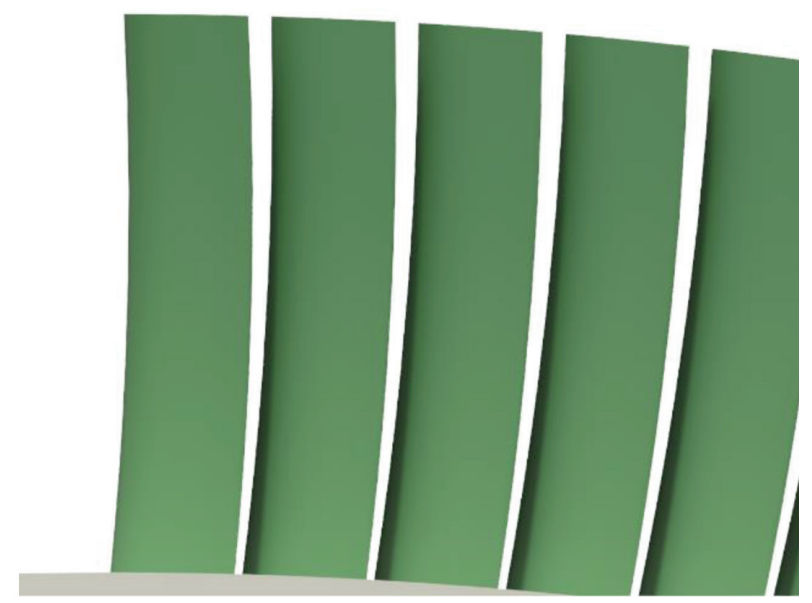

Figure 7: The front view of the rotor with compound circumferential lean.

\subsubsection{Simple and compound axial lean}

The idea of the axial lean is similar to the circumferential lean; however, different effects can be obtained. For the compound lean stator blade, the midspan section move into a region of low pressure. As a consequence, the loading of blade increase [24].

The comparison of the original stage geometry, stage with rotor simple lean and rotor compound lean has been presented in Figs. 8-10.

\subsection{Objective function and constrains}

The isentropic total-to-total efficiency was selected as the objective function for the shape optimisation of the stator and rotor blades. With this definition, the exit kinetic energy losses are not included in general losses of the stage. In order to secure global flow conditions, constraint was imposed on the reaction degree, mass flow rate. 


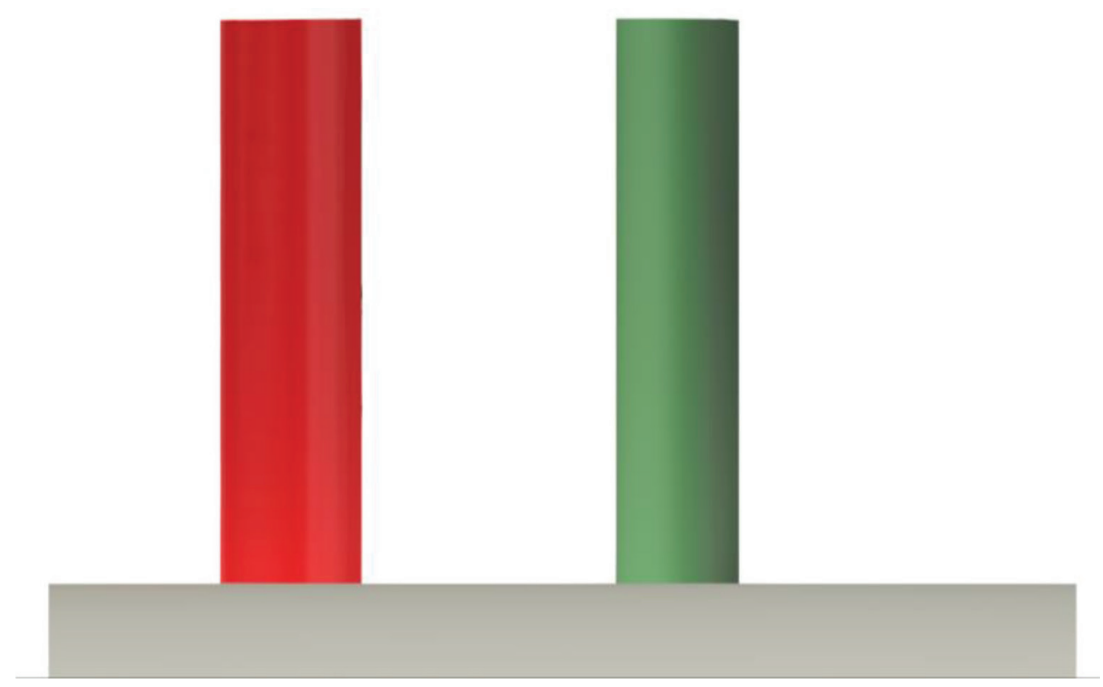

Figure 8: The circumferential view of the original stage.

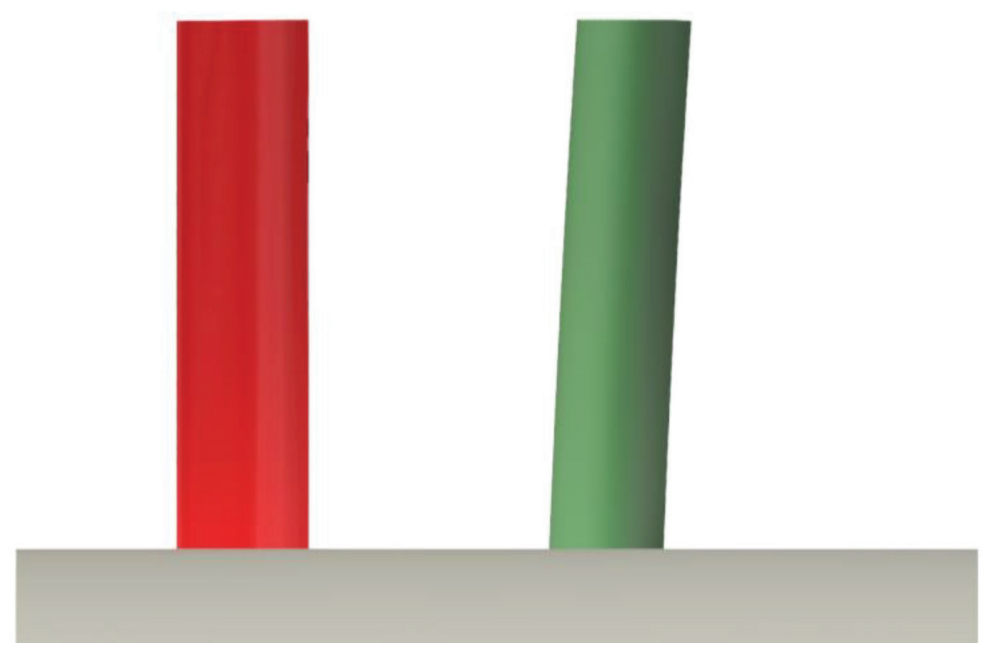

Figure 9: The circumferential view of the stage with simple axial lean of the rotor.

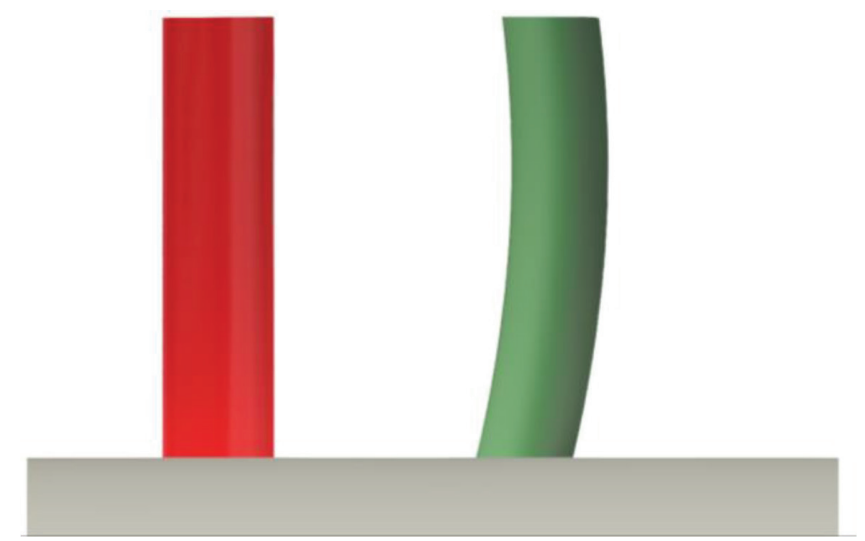

Figure 10: The circumferential view of the stage with compound axial lean of the rotor. 


\subsection{Procedure}

The overall optimisation process consisted of two phases - iterative phase and verification. All stages of the iteration loop were managed by the script written in Matlab application. The geometry of the optimized stage was being created within the Matlab script. In order to perform the CFD analysis, the next step was the generation of suitable computational grid. An automatic grid was created by means of Ansys Turbogrid software. The hexahedral meshes prepared for the numerical simulations consisted of about 200 thousand nodes for every domain (single stator channel and single rotor channel with periodic condition). Special care was given to the edge length ratio, face angle, element volume ratio. During the optimisation, the quality of the meshes was monitored.

The RANS simulations were performed by means of a commercial code Ansys CFX. The numerical model used in the computations was similar to that used by other authors who simulated turbine stages $[25,26]$. The equations describing the flow were solved by means of the finite volume method. Second-order discretization scheme was applied. As a turbulence model the k-w SST was selected. The international standard of state equations for water and steam IAPWS-IF98 was used (version for industrial calculations). The imposed set of boundary conditions consisted of the total pressure and total temperature at the inlet, average static pressure at the outlet and the rotational speed of the rotor domain.

In the verification phase, the optimal geometry was tested on a fine grid ( 2 mln nodes for stage). The comparative results for the original and optimized geometries presented in the paper are those for the refined grids. Three algorithms were used in order to study the optimisation process: Nelder-Mead method [27], Implicit Filtering [28], Hybrid Bat Algorithm. The optimisation scheme was presented in Fig. 12.

\section{RESULTS}

The optimizer chose the following changes of the original geometry of the considered LP stage:

- Stator twist angle increased $0.1875^{\circ}$.

- Stator simple axial lean angle increased $4^{\circ}$.

- Stator simple circumferential lean angle increased $2^{\circ}$.

- Stator compound axial lean increased 0.875 .

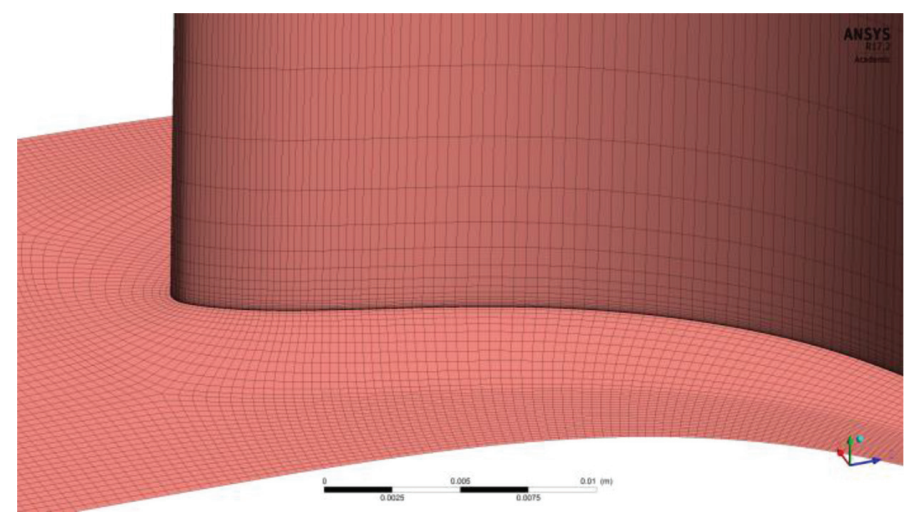

Figure 11: Fine mesh for verification process. 

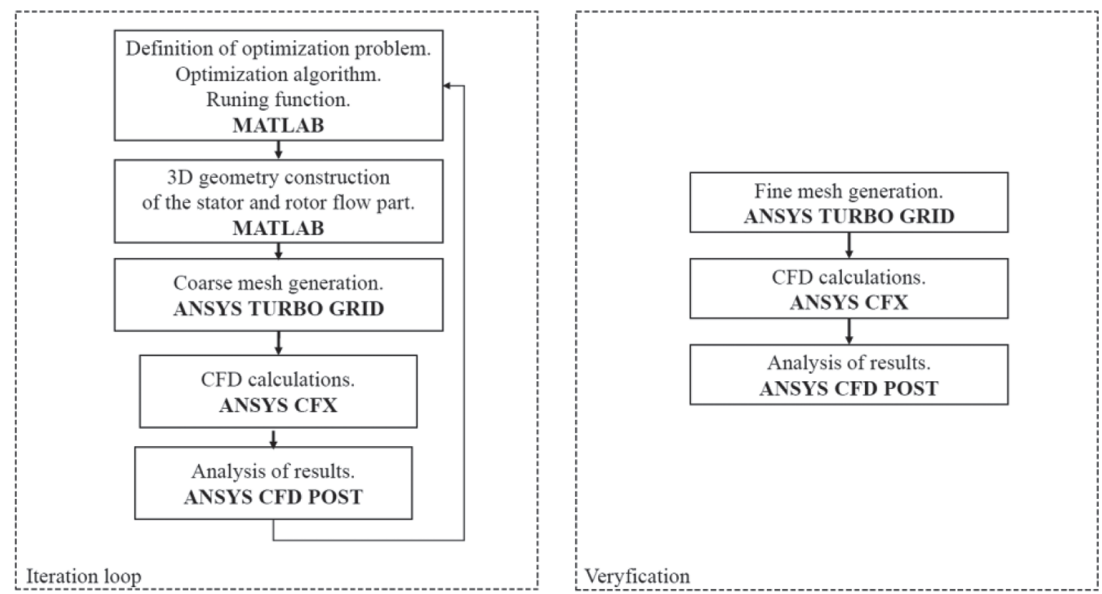

Figure 12: Optimisation strategy description.

- Stator compound circumferential lean increased 1.75 .

- Rotor twist angle decreased $0.1875^{\circ}$ and $0.125^{\circ}$.

- Rotor simple axial lean angle increased $4^{\circ}$.

- Rotor simple circumferential lean angle decreased $2^{\circ}$.

- Rotor compound axial lean increased 0.8125 .

- Rotor compound circumferential lean decreased 2.

As a result of the optimisation process new geometry has been created. The efficiency of optimised flow path increased by about $0.4 \%$ from $96.5 \%$ to $96.9 \%$ (Fig. 13). The best value of objective function was obtained from proposed hybrid method but also other methods resulted in loss reduction. The final geometry was presented in Fig. 14.

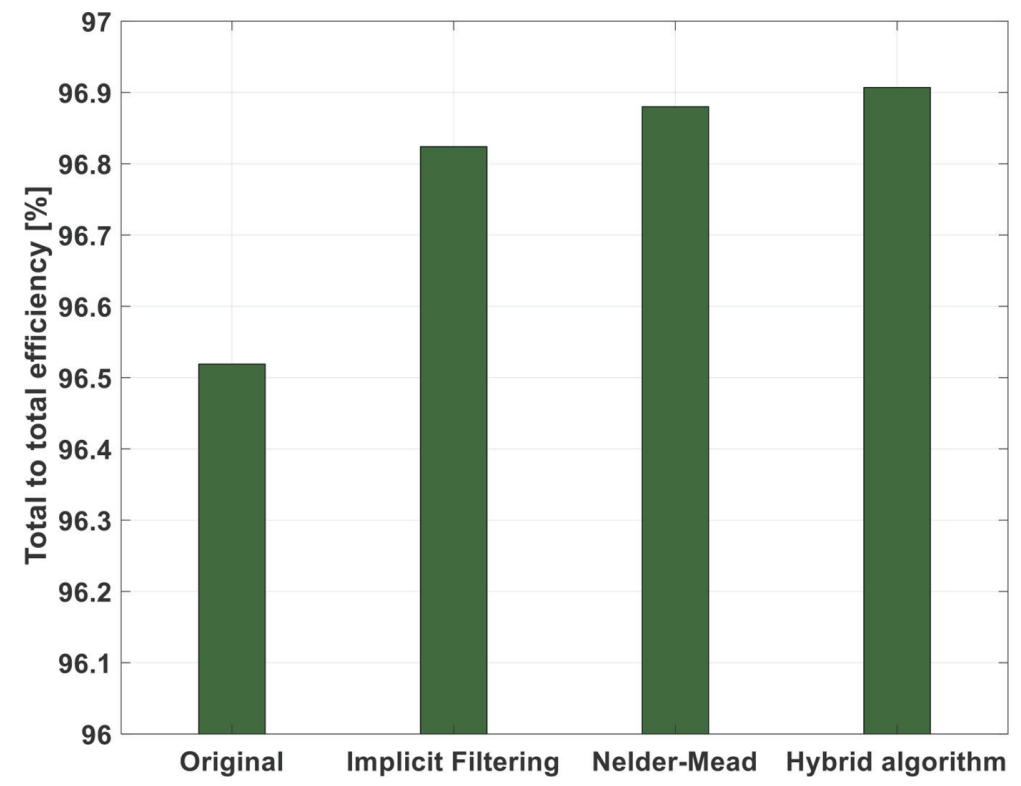

Figure 13: Comparison of total to total efficiency of original and optimized geometries. 


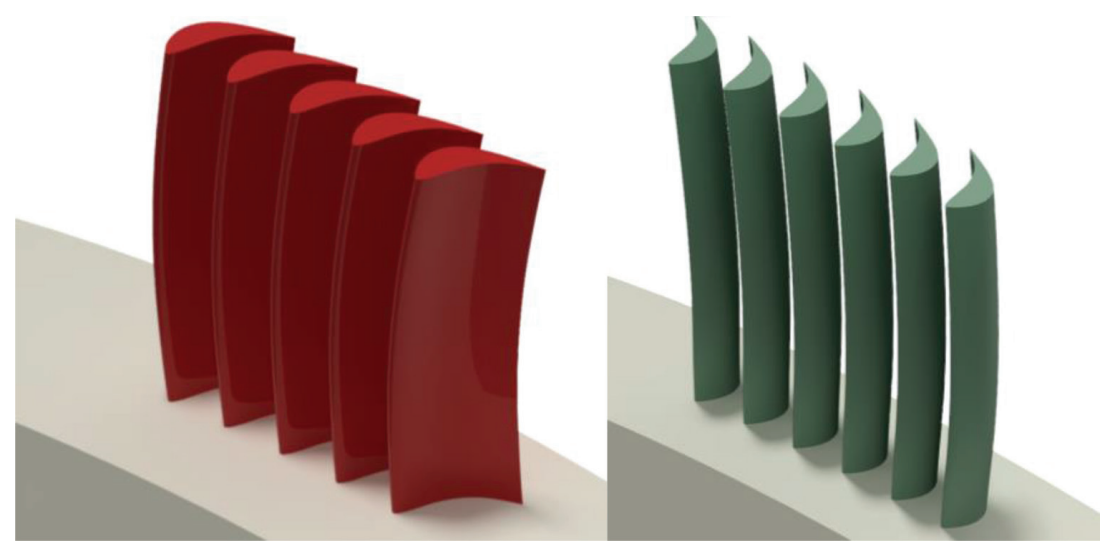

Figure 14: Optimized geometry of LP turbine.

\section{CONCLUSION}

The axial stage was optimized by means of the hybrid optimisation method using the combination of Bat algorithm with Nelder-Mead algorithm. The objective function - the total-to-total isentropic stage efficiency - was obtained from 3D RANS simulations. As the decision variables, the geometrical blade parameters for stator and rotor were selected. They influenced the twisting angle distribution as well as simple and compound circumferential and axial lean.

The optimization of the geometry of the low-pressure axial turbine stage resulted in noticeable efficiency increase equal to 0.4 percentage point. Similar procedure applied for the whole LP turbine part could presumably increase the whole turbine efficiency.

The further work will include new optimisation algorithms. Also, the other optimization objective function will be tested and validated.

\section{ACKNOWLEDGEMENTS}

This work was supported by The National Science Centre, Grant No. 2015/17/N/ST8/01782.

\section{REFERENCES}

[1] Lampart, P. \& Yershov, S., 3D Shape optimiastion of turbomachinery blading. TASK, 6(1), pp. 113-125, 2002.

[2] Lampart, P. \& Hirt Ł., Complex multidisciplinary optimization of turbine blading systems. Archives of Mechanics, 64(2), pp. 153-175, 2012.

[3] Al Jubori, A., Al-Dadah, R.K., Mahmoud, S., Bahr Ennil, A.S. \& Rahbar, K., Three dimensional optimization of small-scale axial turbine for low temperature heat source driven organic rankine cycle. Energy Conversion and Management, 133, pp. 411-426, 2016.

https://doi.org/10.1016/j.enconman.2016.10.060

[4] Elmegaard, B. \& Brix, W., Efficiency of Compressed Air Energy Storage, 24th International Conference on Efficiency, Cost, Optimization, Simulation and Environmental Impact of Energy Systems, pp. 1-12, 2012.

[5] Klonowicz, P., Heberle, F., Preißinger, M. \& Brüggemann, D., Significance of loss correlations in performance prediction of small scale, highly loaded turbine stages working in organic rankine cycles. Energy, 72, pp. 322-330, 2012.

https://doi.org/10.1016/j.energy.2014.05.040 
[6] Beyene, A. \& Miller, A., Krytyczna ocena metod określania strat w turbinowych palisadach profile. Biuletyn Informacyjny Instytutu Techniki Cieplnej Politechniki Warszawskiej, pp. 19-34, 1986. (in Polish).

[7] Kosowski, K., Tucki, K. \& Kosowski, A., Turbine stage design aided by artificial intelligence methods. Expert Systems with Applications, 36(9), pp. 11536-11542, 2009. https://doi.org/10.1016/j.eswa.2009.03.053

[8] Pierret, S. \& Van den Braembussche, R.A., Turbomachinery blade design using a Navier-Stokes solver and artificial neural network. Journal Turbomachinery, 121, pp. 326-332, 1999.

https://doi.org/10.1115/1.2841318

[9] Forrester, A.I.J., Sóbester, A. \& Keane, A.J., Engineering Design via Surrogate Models, Wiley, pp. 23-24, 2008.

[10] Hedar, A. \& Fukushima, M., Minimizing multimodal functions by simplex coding. Optimization Methods and Software, 18(3), pp. 265-282, 2003. https://doi.org/10.1080/1055678031000098773a

[11] Rodriguez, F.J., García-Martinez, C. \& Lozano, M., Hybrid metaheuristics based on evolutionary algorithms and simulated annealing: Taxonomy, comparison, and synergy test. IEEE Transactions on Evolutionary Computation, 16, pp. 787-800, 2012. https://doi.org/10.1109/tevc.2012.2182773

[12] Mahmuddin, M. \& Yousof, Y., A hybrid simplex search and bio-inspired algorithm for faster convergence. International Conference Machine Learning and Computing, 3, pp. 203-207, 2011.

[13] Mirsadeghi, E. \& Shariat Panahi, M., Hybridizing artificial bee colony with simulated annealing. International Journal Hybrid Information Technology, 5, pp. 11-18, 2012.

[14] Jovanovic, R., Kais, S. \& Alharbi, F.H., Cuckoo search inspired hybridization of the Nelder-Mead simplex algorithm applied to optimization of photovoltaic cells. Applied Mathematics Information Science, 10, pp. 961-973, 2016. https://doi.org/10.18576/amis/100314

[15] Yang, X.Y., A New Metaheuristic Bat-Inspired Algorithm. In: Nature Inspired Cooperative Strategies for Optimization (NISCO 2010), Springer Berlin Heidelberg, pp. 65-74, 2010.

[16] Nelder, J.A. \& Mead, R., A simplex method for function minimization. Computer Journal, 7(4), pp. 308-313, 1965. https://doi.org/10.1093/comjn1/7.4.308

[17] Yilmaz, S. \& Küçüksille, E.U., A new modification approach on bat algorithm for solving optimization problems. Applied Soft Computing Journal, 28, 259-275, 2015. https://doi.org/10.1016/j.asoc.2014.11.029

[18] Rezaee Jordehi, A., Chaotic bat swarm optimisation (CBSO). Applied Soft Computing Journal, 26, pp. 523-530, 2015. https://doi.org/10.1016/j.asoc.2014.10.010

[19] Yang, X. \& Gandomi, A.H., Bat algorithm: a novel approach for global engineering optimization. Engineering Computations, 29(5), pp. 464-483, 2012. https://doi.org/10.1108/02644401211235834

[20] Spendley, W., Hext, G. \& Himsworth, F., Sequential application of simplex designs in optimisation and evolutionary operation. Technometrics, 4(4), pp. 441-461, 1962. https://doi.org/10.1080/00401706.1962.10490033 
[21] Yang, X.S., Recent Advances in Swarm Intelligence and Evolutionary Computation, Springer, 2015.

[22] Lampart, P., Numerical Optimization of Stator Blade Sweep and Lean in an LP Turbine Stage. International Joint Power Generation Conference, ASME, pp. 579-592, 2002.

[23] Lampart, P., Control of LP turbine rotor blade underloading using stator blade compound lean at root. Journal of Thermal Science, 9(2), pp. 115-121, 2000. https://doi.org/10.1007/s11630-000-0004-3

[24] Rosic, B. \& Xu, L., Blade lean and shroud leakage flows in low aspect ratio turbines. Journal of Turbomachinery, 134(3), pp. 31003-1-31003-12, 2012. https://doi.org/10.1115/1.3106002

[25] Klonowicz, P., Surwiło, J., Witanowski, Ł., Suchocki, T., Kozanecki, Z. \& Lampart, P., Design and numerical study of turbines operating with MDM as working fluid. Open Engineering, 5, pp. 485-499, 2015. https://doi.org/10.1515/eng-2015-0050

[26] Witanowski, Ł., Klonowicz, P. \& Lampart, P., UWCAES Optimization of a radial-axial turbine working in a UWCAES system. Mechanik, 7, pp. 3-9, 2016.

[27] Lagarias, J., Reeds, J., Wright, M. \& Wrightm P., Convergence properties of Nelder-Mead simplex method in low dimensions. SIAM Journal on Optimization, 9, pp. 112-147, 1998. https://doi.org/10.1137/s1052623496303470

[28] Kelly, C.T., Implicit Filtering, North Carolina State University, Raleigh, North Carolina, 2011. 